\title{
TECNOLOGIAS DE CUIDADO PARA A QUALIDADE DE ASSISTÊNCIA AO PARTO
}

\author{
Karol Trevisan Sartori'; André Vernier Stochero²; Jucimara Michelon \\ Montagner ${ }^{3}$; Dirce Stein Backes ${ }^{4}$; Cláudia Zamberlan ${ }^{5}$
}

\section{RESUMO}

Objetivou-se investigar na percepção das residentes em enfermagem obstétrica as tecnologias de cuidado que promovem melhor qualidade de assistência ao parto. Trata-se de uma pesquisa exploratória e descritiva de abordagem qualitativa. Em relação aos resultados dessa pesquisa a mesma foi dividida em duas partes na qual a primeira referiu-se aos dados sociodemográficos das participantes e a segunda parte salientou questões direcionadas às tecnologias para o trabalho de parto, na qual as mais enfatizadas pelas participantes foram banho morno, massagem lombossacral, deambulação, banqueta, cavalinho, bola suíça, exercícios respiratórios, bamboleio do quadril e aromaterapia. Conclui-se que as tecnologias são importantes subsídios na prestação de cuidados na área obstétrica, e, para isso, os profissionais devem estar capacitados para a utilização segura.

Palavras-chave: Enfermagem Obstétrica; Inovação; Saúde Materna; Tecnologias.

Eixo Temático: Atenção Integral e Promoção à Saúde (AIPS)

\section{INTRODUÇÃO}

A adoção de tecnologias assistenciais para o cuidado torna-se subsídio relevante no suporte da organização e planejamento do trabalho em saúde tendo em vista que qualifica a atenção, humaniza o cuidado e promove melhoria nos indicadores de gestão (BRASIL, 2014).

\footnotetext{
1 Autora/Apresentadora - Bolsista de Iniciação Científica PIBIC-CNPq- Acadêmica do Curso de enfermagem - Universidade Franciscana - UFN. E-mail: karol.sartori@ufn.edu.br

2 Autor/Acadêmico do Curso de Enfermagem - Universidade Franciscana - UFN - E-mail: andrevstochero@gmail.com

${ }^{3}$ Autora/ Mestranda em Saúde Materno Infantil. Universidade Franciscana - UFN - E-mail: enfer.jucimara@gmail.com

${ }^{4}$ Autora/ Co-orientadora Docente do curso de enfermagem- Universidade Franciscana - UFN - Email: backesdirce@ufn.edu.br

${ }^{5}$ Autora/ Orientadora. Docente do curso de Enfermagem - Universidade Franciscana - UFN - E-mail: claudiaz@ufn.edu.br
} 
O enfermeiro exerce a gestão do cuidado nas maternidades de modo a facilitar a assistência prestada à tríade, parturiente, bebê e família. Nesse enfoque, ele utiliza ferramentas gerenciais que possibilitam a organização, o planejamento, à coordenação e execução do cuidado, o que permite melhorias em todos os processos de gestão (MAZIERO et al., 2014).

Dentre estas ferramentas destacam-se as tecnologias de cuidado no trabalho de parto, as quais contribuem para que, esse momento, seja permeado de qualidade no parir, assim como, estimula os aspectos fisiológicos desse período. No intuito de reconhecer quais tecnologias são mais prevalentes e articuladas nessa fase gestacional questiona-se: Quais tecnologias de cuidado promovem melhor qualidade de assistência ao parto, na percepção das residentes em enfermagem obstétrica?

Nesse enfoque tem-se como objetivo investigar na percepção das residentes em enfermagem obstétrica as tecnologias de cuidado que promovem melhor qualidade de assistência ao parto.

\section{METODOLOGIA}

Trata-se de uma pesquisa exploratória e descritiva de abordagem qualitativa. Os dados foram coletados com as residentes do segundo ano em Enfermagem Obstétrica da Universidade Franciscana (UFN), por meio de um questionário que foi encaminhado para as mesmas via e-mail. Neste instrumento foi enfatizado o perfil sócio demográfico das participantes e em uma segunda parte questões específicas acerca das tecnologias de cuidado para o trabalho de parto.

Para a realização desta pesquisa foram seguidos os aspectos éticos de pesquisa com seres humanos, conforme a Resolução 466/12 do Conselho Nacional de Saúde (BRASIL, 2012). O projeto foi para apreciação no Comitê de Ética da Instituição de Ensino e aprovado sob protocolo número: 4.504.024.

\section{RESULTADOS E DISCUSSÕES}

A partir dos dados coletados destaca-se que o sexo das participantes é predominantemente feminino e a idade dominante é de 25 anos. Todas possuem 
ensino superior completo e são residentes do segundo ano em Enfermagem Obstétrica na Universidade Franciscana (UFN). A respeito do tempo de formação, uma delas é formada há 3 anos e as outras duas há 1 ano e 2 meses. Já o tempo que as mesmas atuam na área varia de 1 ano a 1 ano e 8 meses e o tempo que estão na instituição é de 8 meses, 1 ano e 1 ano e 1 mês.

Destaca-se a importância dos Programas de Residência em Enfermagem Obstétrica, visto que a Enfermagem Obstétrica (EO) é de suma importância para promover a humanização do cuidado à gestante, com o propósito de garantir um atendimento de qualidade, adequado e integral (GIANTÁGLIA et al., 2020).

A função da residência auxilia no fortalecimento da assistência prestada, na importância do empenho da equipe multiprofissional, humanizando os processos de trabalho, de modo qualificado e seguro, formando gradativamente uma assistência integral e de qualidade as puérperas (DAL MOLIN; SILVA; PEDROSO, 2018).

A segunda parte da pesquisa salientou questões direcionadas às tecnologias de cuidado para o trabalho de parto, que são aqueles cuidados prestados à paciente, com o objetivo de confortar, orientar e promover saúde e autocuidado.

As tecnologias mais enfatizadas pelas participantes foram banho morno, massagem lombossacral, deambulação, banqueta, cavalinho, bola suíça, exercícios respiratórios, bamboleio do quadril e aromaterapia. Cada técnica possui uma finalidade e para isso os profissionais devem ser capacitados para a utilização segura. Existe uma singularidade em relação a como cada parturiente sente e entende a dor, assim como quanto ao uso dessas tecnologias não invasivas de alívio da dor exige que as mulheres tenham um maior senso de controle sobre seu corpo e emoções, desse modo a humanização torna-se fator relevante nestes cenários (JANTSCH; SCHUSER, 2020).

Essas tecnologias não-invasivas, sãos as técnicas, procedimentos e saberes utilizados pelos profissionais de enfermagem no processo de cuidar da parturiente, tendo como principal característica o não-invasivo, permitindo que a gestante desempenhe seus instintos durante o momento do parto e tornem-se protagonistas (VARGENS et al., 2017). 
Em suma, as tecnologias podem fornecer um relaxamento muscular progressivo, cujo objetivo é fornecer tensão muscular e melhorar a oxigenação uterina, o que ajuda a economizar energia para o controle psíquico e sendo benéfico entre as contrações uterinas (JANTSCH; SCHUSER, 2020).

As puérperas devem ter acesso às tecnologias não-invasivas durante 0 trabalho de parto, em virtude de estas influenciarem positivamente na dor e no desconforto, e reduzindo a duração do trabalho de parto, traumas perineais, ansiedade e estresse, propiciando autoconfiança e conforto para a parturiente (ROPKE, 2016).

\section{CONCLUSÃO}

Conclui-se que as tecnologias são importantes ferramentas de cuidados na área obstétrica, e, para isso, os profissionais devem estar capacitados para a utilização segura, tendo em vista que o parto é um momento único para a mulher e a mesma necessita de toda atenção dos profissionais.

Além disso, o trabalho de parto e o nascimento podem favorecer a autonomia das mulheres, porém devem ser oferecidas como uma opção de cuidado, e, as parturientes, necessitam ser orientadas e esclarecidas acerca do uso dessas tecnologias.

\section{AGRADECIMENTOS}

Agradeço à minha orientadora Professora Cláudia Zamberlan, minha Coorientadora e demais autores pela ajuda na construção deste artigo. Agradeço também pela minha bolsa de Iniciação Científica PIBIC/CNPq pela oportunidade e a instituição Universidade Franciscana - UFN.

\section{REFERÊNCIAS}

BRASIL. Conselho Nacional de Saúde. Resolução 466, de 12 de dezembro de 2012.

em: 
EDUCAÇÃO, SAÚDE

ETECNOLOGIA

http://www.conselho.saude.gov.br/resolucoes/2012/Reso466.pdf. Acesso em 3 de agosto 2021.

BRASIL. Ministério da Saúde. Humanização do parto e do nascimento. Cadernos humaniza SUS. Vol. 5, Pág. 1-459, 2014. Disponível em: https://www.redehumanizasus.net/sites/default/files/caderno humanizasus v4 huma nizacao parto.pdf. Acesso em 03 agosto de 2021.

DALMOLIN, D; SILVA, M .V. F .B; PEDROSO, M. V. A Importância da Residência em Enfermagem Obstétrica na Fortificação e Consolidação da Assistência ao Parto de Risco Habitual exercida por Enfermeiros Obstetras: Relato de Experiência. Anais do Congresso Brasileiro de Enfermagem Obstétrica e Neonatal. 2018. Disponível em: https://www.even3.com.br/anais/cobeon/63719-a-importancia-daresidencia-em-enfermagem-obstetrica-na-fortificacao-e-consolidacao-da-assistenciaao-parto-de-ris/. Acesso em 23 de agosto de 2021.

GIANTÁGLIA, F. N., et al. Humanização do cuidado em um programa de residência enfermagem obstétrica: possibilidades e desafios. Enfermería: Cuidados Humanizados. Vol. 9 n². Pág. 114-128, 2020. Disponível em: http://www.scielo.edu.uy/scielo.php?script=sci arttext\&pid=S239366062020000200114. Acesso em: 23 de agosto de 2021.

JANTSCH, N; SCHUSER, R.V. Tecnologias não invasivas de cuidado no parto: uma revisão integrativa. Revista Destaques Acadêmicos UNIVATES. Lajeado, Vol. 12, no3, Pág. 388-404, 2020. Disponível em: http://www.univates.com.br/revistas/index.php/destaques/article/view/2692/1728. Acesso em 23 de agosto de 2021.

MAZIERO, V. G.; BERNARDES, A.; SPIRI, W.C.; GABRIEL, C.S. Construindo significados sobre gerência da assistência: um estudo fenomenológico. Ciênc Cuid Saúde. Vol.13, $\mathrm{n}$ ‥3, Pág.563-70, 2014. Disponível em: 


\section{QUFN}

http://www.periodicos.uem.br/ojs/index.php/CiencCuidSaude/article/view/23245/pdf 230. Acesso em 03 de agosto de 2021.

ROPKE, J. Uso de tecnologias não invasivas para alívio da dor durante o processo de parturição. Femina. Vol.44, no2, Pág 137-14, 2016. Disponível em: https://docs.bvsalud.org/biblioref/2020/02/1050859/femina-2016-442-137-141.pdf. Acesso em 17 de agosto de 2021.

VARGENS, O. M. C, et al. Tecnologias não-invasivas de cuidado de enfermagem obstétrica: repercussões sobre a vitalidade do recém-nascido. Rev enferm UERJ. Rio de Janeiro, Vol. 25, Pág. 1-7, 2017. Disponível em: https://www.epublicacoes.uerj.br/index.php/enfermagemuerj/article/view/21717/22670. Acesso em 23 de agosto 2021. 